\title{
Reducing the mother-to-child transmission of HIV: findings from an early infant diagnosis program in Delta state Nigeria
}

\author{
Judith A. Ibobo, Ezekiel Uba Nwose*, Hellen Chime
}

Department of Public and Community Health, Novena University, Ogume, Delta State, Nigeria

Received: 13 October 2017

Accepted: 31 October 2017

\section{*Correspondence:}

Dr. Ezekiel Uba Nwose,

E-mail: enwose@csu.edu.au

Copyright: ( $)$ the author(s), publisher and licensee Medip Academy. This is an open-access article distributed under the terms of the Creative Commons Attribution Non-Commercial License, which permits unrestricted non-commercial use, distribution, and reproduction in any medium, provided the original work is properly cited.

\begin{abstract}
Background: Mother-to-child transmission (MTCT) of HIV has been a global issue being addressed with prevention of mother to child transmission (PMTCT) strategy. Nigeria is said to be responsible for $30 \%$ of the global burden of MTCT of HIV. Hence, Delta state of Nigeria had implemented its own PMTCT in line with the global plan to eliminate MTCT. This paper evaluates the determinants and level of effectives of PMTCT with a view to develop a framework to review the program in Delta state.

Methods: This was a narrative literature review which aimed at appraising available reports on PMTCT services and related data. In particular, the 'Delta state development performance: health sector report 1991-2013' was appraised.

Results: Generally, Delta state has improved on infant survival better than national baseline. Specifically, on PMTCT, more women (average 2.9\%) than men (average $2.1 \%$ ) have tested positive for HIV in the 5 years period of 2008-2012 free screening. Further, the report indicates that the State has achieved $78 \%$ of eligible facilities offering PMTCT services in the state, but only $23 \%$ coverage of pregnancies.

Conclusions: In the context of cost effectiveness as well as improvement in service delivery, there is a need to investigate the success rates of health facilities that are offering PMTCT services. There is also need to investigate the barriers to PMTCT that may be prevailing in Delta state.
\end{abstract}

Keywords: Delta state of Nigeria, Early infant diagnosis, HIV/AIDS, MTCT, PMTCT

\section{INTRODUCTION}

It is agreed that mother-to-child transmission (MTCT) is the dominating cause of HIV infection in children below the age of 15 years. ${ }^{1}$ Where blood transfusion services as well as use of needles and syringes follow are done according to standard practice, MTCT appears to be the only source HIV infection in young children. ${ }^{2}$ While AIDS epidemic has claimed the lives of millions of people including children and other millions are living with HIV/AIDS today, HIV testing has remained a public health issue. Specifically, strategies for PMTCT are suboptimal in several countries. This is confounded by several determinants of women's willingness to volunteer to do the test. ${ }^{3}$ Progress are being made, but there is no room for complacency.

African countries were arguably among the earliest to be affected by HIV and the epidemics in continent are well advanced. However, the virus has already spread all over the world and affecting all age groups. It is initially denoted to be a sexually transmitted disease/infection, but knowledge of vertical transmission from mother to child has long been established. For instance, the number of infants who acquire the virus from their mothers is rising rapidly in a number of places, notably India and SouthEast Asia. ${ }^{4,5}$ The effects of the epidemic among young children are serious and far-reaching. Indeed, HIV/AIDS has threatened to reverse the improvement already 
achieved in child survival and worsened infant mortality in the worst affected countries. In Zimbabwe, for instance, infant mortality increased from 3\% in 1990 to $6 \%$ in 1996 , which amounts to $100 \%$ increase in 6years period. Meanwhile, deaths among the subpopulation below 5 year-olds increased from $0.8 \%$ to $2 \%$ in the same period. ${ }^{6}$ That is, while death rate among children was unacceptably $100 \%$, it is worse among the age group that forms the bulk of child AIDS deaths.

\section{PREVENTION STRATEGIES AND PROGRESS ACHIEVED}

Several strategies have been proposed and review. For instance, there has been 2006 guideline and an updated revisions by the World Health Organization (WHO), that were based on systematic review of progress. ${ }^{7,8}$ Yet, the results of the many studies pose important questions such as differences in long-term benefits between treatment options, after accounting for confounding factors, as well as consideration of affordances in low-mid income countries (LMIC). ${ }^{9}$

Until recently, countries had only two main strategies for limiting the numbers of HIV-infected infants:

- Primary prevention of MTCT-taking steps to protect women of childbearing age from becoming infected with HIV in the first place;

- The provision of family planning services, and pregnancy termination where this is legal, to enable women to avoid unwanted births.

These remain the most important strategies for reducing HIV among young children and essential activities in all national AIDS campaigns.

Today, however, there is a third option for HIV-positive women who want to give birth which consists of a course of antiretroviral drugs for the mother (and sometimes the child), and replacement feeding for the infant. A recent trial in Thailand using a short course of zidovudine has shown that this strategy is able to reduce the risk of MTCT to below $10 \%$ when breastfeeding is strictly avoided. $^{10,11}$

\section{Progress among pregnant and breastfeeding women}

The proportion of pregnant women living with HIV receiving ART was said to have worsened in 21 of the 22 global plan priority countries from $36 \%$ in 2009 , to $80 \%$ in 2015. Perhaps more importantly, $93 \%$ of pregnant women receiving treatment were receiving lifelong treatment, up significantly from $73 \%$ in 2014 . India does not feature in the latest data. ${ }^{12}$ In 2015, six priority countries (Botswana, Mozambique, Namibia, South Africa, Swaziland and Uganda) met the global plan target of reducing mother-to-child transmission by $90 \%$. Outside of the priority countries, in mid-2015; Cuba became the first country to eliminate the mother-to-child transmission of HIV. In 2016, Belarus and Armenia achieved the same feat while Thailand became the first country in the Asia and Pacific region to eliminate MTCT. As PMTCT is not $100 \%$ effective, elimination is defined as a reduction of transmission to such low levels that it no longer constitutes a public health problem. ${ }^{13}$

\section{PMTCT program in Nigeria: a brief critical review}

Level of MTCT in Nigeria was reported to be about $32 \%$ of world figure; and that only a third of patients eligible of PMTCT were receiving it (Figure 1). As at 2015, success rates in terms of reduction in incidence of new $\mathrm{HIV}$ in children and increase in HIV-infected pregnant women receiving anti-retroviral indicated Nigeria to have performed worst (Figure 2). ${ }^{14}$ Figure 1 further indicates that percentage of children with HIV who are receiving treatment in 2016 report is less than the level of PMTCT achievement of 2013. However, the reports did not indicate levels of achievement in Delta state.

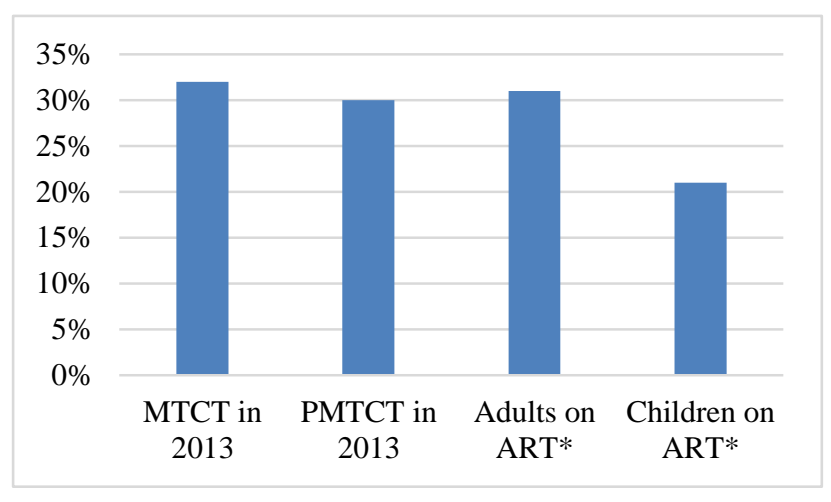

Figure 1: Success rate of Nigeria in 2013 and 2016 reports.

*2016 report.

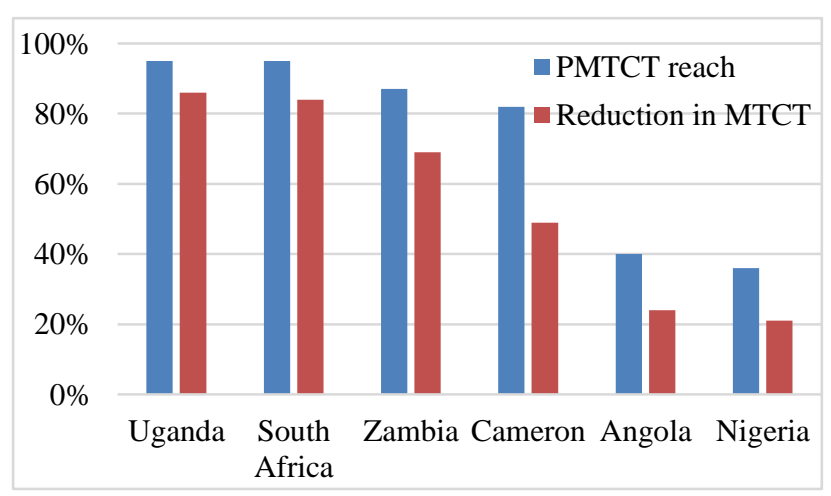

Figure 2: Success rate of Nigeria relative to other African countries in a 2015 report.

\section{Early infant diagnosis program in Delta state Nigeria}

In Delta state, there has been concerted effort to reduce infant mortality rate and available data indicate some level of success, especially when compared with national baseline (Table 1). Health program on HIV and AIDS 
control was established in 2005 with a focus on PMTCT (including provision of ART at subsidized cost) among other goals. Between 2008 and 2012, a total of 13400 males and 30895 females were benefited from free HIV screening whereby it was indicated that prevalence of HIV was significantly more in women than men (Figure 3). A scale-up plan lead to $78 \%$ of eligible facilities offering PMTCT services in the state, but achievement was indicated to be only $23 \%$ coverage of estimated pregnancies. $^{15}$

Table 1: Delta state vs. national baseline mortality rates. $^{15}$

\begin{tabular}{|c|c|c|}
\hline & $\begin{array}{l}\text { Infants } \\
(\%)\end{array}$ & $\begin{array}{l}\text { Under } 5 \text { years } \\
(\%)\end{array}$ \\
\hline Live births 2003 & 4.8 & 10.2 \\
\hline Live births 2006 & 6.8 & 5.4 \\
\hline Live births 2012 & 3.7 & 5.2 \\
\hline National baseline 1990 & 9.1 & 19.1 \\
\hline National baseline 2015 & 3.1 & 6.4 \\
\hline
\end{tabular}

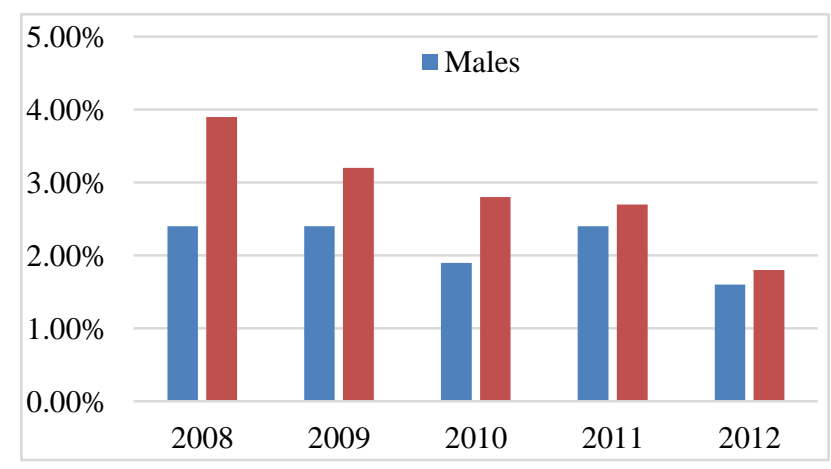

Figure 3: Prevalence rates of HIV based on free screening of 2008-2012. ${ }^{15}$

\section{Progress among children}

Between 2009 and the end of 2015, there was a $60 \%$ decline in new HIV infections among children in the Global Plan priority countries, from 270,000 to 110,000 , equating to 1.2 million averted infections. This compares to a fall of just $24 \%$ between 2000 and 2008, meaning that the rate of the decline in new infections since the launch of the global plan nearly tripled. Without Nigeria, the remaining countries reduced new HIV infections by $69 \%$. While this progress is encouraging, it is significantly below the $90 \%$ target. However, some countries got close to this target including Uganda (86\%), South Africa and Burundi (both 84\%). Botswana, Burundi, Namibia and Swaziland had fewer than 1,000 new infections in 2015. These are small enough numbers that, with determined efforts, could be reduced dramatically. Other countries still face significant challenges to rolling out effective PMTCT services. Angola, Cote d'Ivoire and Nigeria have registered a less than $40 \%$ reduction in new HIV infections among children since 2009. ${ }^{19}$ Barriers to the uptake of PMTCT programs As well as the scale-up of PMTCT, a number of barriers need to be overcome in order to increase access to these services. 8

\section{Knowledge about HIV, MTCT and PMTCT}

A number of studies have identified the link between knowledge of HIV, MTCT and PMTCT and uptake of PMTCT services. For example, research from Cameroun indicated that among pregnant women, all respondents in the study were aware of HIV infection, but only $76.7 \%$ had adequate knowledge on its routes of transmission and $79.3 \%$ were aware of MTCT. ${ }^{16}$ This is similar to a report from Nigeria that indicated approximately $18 \%$ of mothers being unaware of infant HIV screening. ${ }^{17}$

\section{Confusion over exclusive breastfeeding}

One study from Malawi has reported that while the majority of mothers chose to exclusively breastfeed, some reported mixed feeding in the first six months. ${ }^{18} \mathrm{~A}$ number of reasons were given for this including traditional feeding practices including a poor communication and/or understanding of about exclusive breastfeeding. ${ }^{19,20}$ For instance, a research from Tanzania compared two hospitals that offered different infant feeding options. Hospital A promoted exclusive breastfeeding as the only infant feeding option, while hospital B followed Tanzanian PMTCT infant feeding guidelines which promote patient choice. Women in hospital A trusted the advice given and were confident in their ability to exclusively breastfeed, whereas women in hospital B expressed confusion and uncertainty about how to best feed their infants. ${ }^{21}$

\section{MAJOR ISSUES FOR DECISION-MAKING}

\section{The cost of inaction}

The cost of doing nothing to reduce MTCT will depend on a great deal on the prevalence of HIV infection among parents-to-be. In areas where $20 \%$ or more of pregnant women are HIV-positive, the financial cost of caring for sick and dying HIV-infected children will be enormous, and there will be a significant loss of the benefits from the huge commitment of time, energy and resources spent on reducing child morbidity and mortality over recent decades. ${ }^{22}$ Where HIV prevalence is low, health care costs will be relatively low too, and the waste of resources already spent on child survival not quite so dramatic. However, the costs for families and communities cannot be measured in financial terms alone, and many couples will bear responsibility for looking after their infected babies, often while struggling to cope with their own ill-health.

\section{Counseling and voluntary testing}

It is general knowledge that for people to take advantage of a health program such as PMTCT, they will need to know and accept their HIV status; the service needs to be available in the context of accessible and affordable. That 
is, everyone should have access to such services. People who know they are HIV-infected are likely to be motivated to look after their health, perhaps with behaviour and lifestyle changes, and to seek early medical attention for problems. They can make informed decisions about sexual practices, childbearing, and infant feeding, and take steps to protect partners who may still be uninfected. Those whose test results are negative can be counselled about how to protect themselves and their children from infection. Furthermore, voluntary counselling has an important role to raise awareness of PMTCT. ${ }^{23}$ In a study reported from Nigeria, two of the four barriers to early infant diagnosis (i.e. barrier to PMTCT) included that $18 \%$ of mothers were unaware about infant screening and $79 \%$ complained of distance. ${ }^{17}$

Taking local conditions into account, therefore, policymakers need to review public health counseling and testing availability - to reach the target women or couples; and to site reproductive health services in areas within accessible distance of the women attending antenatal services as part of a programme to reduce. ${ }^{24}$ There is also the requirement for policy-makers to take into account the risks of undermining breastfeeding generally and relaxing vital controls such as the promotion of infant formula by the industry. ${ }^{25}$

\section{Stigma and discrimination}

Where women fear social vices such as discrimination and stigmatization, if they are identified as HIV-infected, they will be reluctant or completely unable to take advantage of opportunities offered to protect their infants from infection. In the study reported from Nigeria, the other two of four barriers to PMTCT included that $39 \%$ of mothers were afraid of discrimination and stigma, which was corroborated by $44 \%$ of the women indicating spouse disapproval of the health program. ${ }^{17}$

\section{GUIDELINES VS. TARGETS}

There have been guidelines regarding PMTCT. In September 2015, the WHO released new guidelines recommending lifelong antiretroviral treatment for all pregnant and breastfeeding women living with $\mathrm{HIV}{ }^{8}$ Obvious among the guidelines and targets are:

\section{Guidelines for pregnant and breastfeeding women living with HIV}

This provides that treatment should be maintained after delivery and completion of breastfeeding for life. There is the 2013 version that included option B that prescribes treatment to be only continued after the completion of breastfeeding, if the mother is on ART. ${ }^{8,26}$

\section{Guidelines for HIV-exposed infants}

This prescribes for all infants born to HIV-positive mothers to receive a course of ART immediately after birth; and the treatment is recommended to be determined by mother's ART regimen as well as the infant feeding method. It also prescribes that at four to six weeks old, such infants should be screened for early diagnosis with a repeat test at 18 months and/or when breastfeeding ends. $^{27}$

\section{Global PMTCT targets}

In 2011, a global plan was launched to reduce the number of new HIV MTCT infections by $90 \%$ by 2015 . The WHO identified 22 priority countries for $75 \%$ of the global PMTCT service need. ${ }^{28}$ Targets relating to PMTCT include commitment to ensure that $95 \%$ of pregnant women living with HIV are receiving lifelong HIV treatment by $2018 .^{8}$

\section{Opinion on guidelines vs. targets}

Looking the foregoing, it seems the guidelines are lacking in emphasis on 'determinants of acceptance' of PMTCT, especially as may be specific for Nigeria and Delta state in particular. For instance, the following are yet to be conspicuous in the guidelines and research discussions regarding factors affecting PMTCT programs:

1. Infidelity among people in polygamous marriages.

2. Trust among people in monogamous marriages.

3. Pre-marital risky sexual behaviour among people in monogamous marriages. $^{29}$

4. Abstinence from sex among people who are religiously faithful, especially Muslims.

In terms of cost-benefit analysis, especially for policy makers to decide on affordable program; the above four factors seem to constitute gap in knowledge and practice. ${ }^{30,31}$ That is, it is pertinent to evaluate how these factors are impacting on PMTCT success rates.

\section{CONCLUSION}

MTCT are been relatively reduced with effective PMTCT interventions. However, reports of progress in Nigeria leave much to be desired. There is indication of $23 \%$ coverage of estimated pregnancies in Delta state, but as yet neither comparative evaluation of actual success rate of PMTCT in Delta state relative to other states within the country, nor determination of the barrier in terms of the local conditions.

\section{ACKNOWLEDGEMENTS}

This work is a prelude to public health dissertation into evaluation of the effectiveness of governmental public health program on reducing the MTCT of HIV in Delta state, Nigeria.

\section{Funding: No funding sources Conflict of interest: None declared Ethical approval: Not required}




\section{REFERENCES}

1. Parameshwari S, Jacob MS, Vijayakumari J, Shalini D, Sushi MK, Sivakumar M. A program on prevention of mother to child transmission of HIV at government hospital, Tiruchengode Taluk, Namakkal District. Indian J Community Med. 2009;34(3):261-3.

2. Ubesie AC, Emodi IJ, Ikefuna AN, Ilechukwu GC, Ilechukwu GCA. Prevalence of human immunodeficiency virus transmission among transfused children with sickle cell anemia in Enugu Nigeria. Ann Med Health Sci Res. 2012;2(2):10913.

3. Ben-Natan M, Hazanov Y. Women's willingness to be tested for human immunodeficiency virus during pregnancy: A review. World J Virol. 2015;4(3):24554.

4. Chandrasekaran P, Dallabetta G, Loo V, Rao S, Gayle H, Alexander A. Containing HIV/AIDS in India: the unfinished agenda. The Lancet infectious diseases 2006;6(8):508-21.

5. Ruxrungtham K, Brown T, Phanuphak P. HIV/AiDS in Asia. Lancet. 2004;364(9428):69-82.

6. Bassett MT, Mhloyi M. Women and AIDS in Zimbabwe: the making of an epidemic. Int J Health Services. 1991;21(1):143-56.

7. World Health Organization. Antiretroviral drugs for treating pregnant women and preventing HIV infection in infants. Available at: http://whqlibdoc. who.int/publications/2010/9789241599818_eng.pdf. Accessed on 4 August 2017.

8. World Health Organization. Consolidated guidelines on the use of antiretroviral drugs for treating and preventing HIV infection: Recommendations for a public health approach - Second edition. Available at: http://www.who.int/hiv/pub/arv/arv-2016/en/. Accessed on 4 August 2017.

9. Lallemant M, Jourdain G. Preventing mother-tochild transmission of HIV: Protecting this generation and the next. $\mathrm{N}$ Eng $\mathrm{J}$ Med. 2010;363(16):1570-2.

10. Coutsoudis A. Breast-feeding and HIV transmission. Nutrition research reviews. 2001;14(2):191-206.

11. Rollins N, Meda N, Becquet R, Coutsoudis A, Humphrey J, Jeffrey B, et al. Preventing postnatal transmission of HIV-1 through breast-feeding: modifying infant feeding practices. J Acquir Immune Defic Syndr. 2004:35(2):188-95.

12. Watts DH. Management of human immunodeficiency virus infection in pregnancy. $\mathrm{N}$ Eng J Med. 2002;346(24):1879-91.

13. CDC. Monitoring selected national HIV prevention and care objectives by using HIV surveillance data-United States and 6 US dependent areas2010. 2012.

14. AVERT. Prevention of mother-to-child transmission (PMTCT) of HIV. Available at: https://www.avert. org/professionals/hiv-programming/prevention/ prevention-mother-child. Accessed on 3 August 2017.

15. Office of the Senior Adviser to the Governor on Foreign Relations. Delta State development performance: Health sector report 1991-2013. Available at: http://www.undp.org/content/dam/ nigeria/docs/IclusiveGrwth/UNDP_NG_DeltaState_ Health_2015.pdf. Accessed on 12 August 2017.

16. Sama CB, Feteh VF, Tindong M, Tanyi JT, Bihle NM, Angwafo FF. Prevalence of maternal HIV infection and knowledge on mother-to-child transmission of HIV and its prevention among antenatal care attendees in a rural area in northwest Cameroon. PLoS One. 2017;12(2):e0172102.

17. Edoni E. Barriers to uptake of polymerase chain reaction testing for HIV exposed infants at six weeks among PMTCT mothers at the State Hospital Osogbo, Nigeria. AIDS Research and Human Retroviruses. 2014;30(1):266.

18. Petra Study Team. Efficacy of three short-course regimens of zidovudine and lamivudine in preventing early and late transmission of HIV-1 from mother to child in Tanzania, South Africa, and Uganda (Petra study): a randomised, double-blind, placebo-controlled trial. Lancet. 2002;359(9313):1178-86.

19. Kasenga F, Hurtig A-K, Emmelin M. Home deliveries: implications for adherence to nevirapine in a PMTCT programme in rural Malawi. AIDS Care. 2007;19(5):646-52.

20. Shapiro RL, Hughes M, Ogwu A, Kitch D, Lockman S, Moffat C, et al. Antiretroviral regimens in pregnancy and breast-feeding in Botswana. $\mathrm{N}$ Eng J Med. 2010;362(24):2282-94.

21. Dabis F, Bequet L, Ekouevi DK, Viho I, Rouet F, Horo A, et al. Field efficacy of zidovudine, lamivudine and single-dose nevirapine to prevent peripartum HIV transmission. AIDS (London, England). 2005;19(3):309.

22. American College of Obstetricians and Gynecologists. ACOG Practice bulletin no. 115: Vaginal birth after previous cesarean delivery. Obstet Gynecol. 2010;116(2):450-63.

23. Piot P, Bartos M, Larson H, Zewdie D, Mane P. Coming to terms with complexity: a call to action for HIV prevention. Lancet. 2008;372(9641):84559.

24. Panel on Treatment of HIV-Infected Pregnant Women and Prevention of Perinatal Transmission. Recommendations for use of antiretroviral drugs in pregnant HIV-1-infected women for maternal health and interventions to reduce perinatal HIV transmission in the United States. Available at: https://aidsinfo.nih.gov/contentfiles/lvguidelines/Per inatalGL.pdf. Accessed on 14 August 2017.

25. Rupali P, Condon R, Roberts S, Wilkinson L, Voss L, Thomas M. Prevention of mother to child transmission of HIV infection in Pacific countries. Internal Med J. 2007;37(4):216-23. 
26. Ahmed S, Kim MH, Abrams EJ. Risks and benefits of lifelong antiretroviral treatment for pregnant and breastfeeding women: a review of the evidence for the Option B+ approach. Current opinion in HIV and AIDS. 2013;8(5):474-89.

27. Richardson BA, Otieno PA, Mbori-Ngacha D, Overbaugh J, Farquhar C, John-Stewart GC. Hormonal contraception and HIV-1 disease progression among postpartum Kenyan women. AIDS (London, England). 2007;21(6):749.

28. Lauer JA, Betrán AP, Barros AJ, de Onís M. Deaths and years of life lost due to suboptimal breastfeeding among children in the developing world: a global ecological risk assessment. Public Health Nutr. 2006;9(6):673-85.

29. Calsyn DA, Campbell AN, Tross S, Hatch-Maillette MA. Is monogamy or committed relationship status a marker for low sexual risk among men in substance abuse treatment? Clinical and methodological considerations. Am J Drug Alcohol Abuse. 2011;37(5):294-300.

30. Aliyu MH, Blevins M, Audet C, Shepherd BE, Hassan A, Onwujekwe O, et al. Optimizing PMTCT service delivery in rural North-Central Nigeria: protocol and design for a cluster randomized study. Contemp Clin Trials. 2013;36(1):187-97.

31. Fronczak N, Oyediran KA, Mullen S, Kolapo UM. Dual indices for prioritizing investment in decentralized HIV services at Nigerian primary health care facilities. Health Policy Planning. 2016;31(3):377-89.

Cite this article as: Ibobo JA, Nwose EU, Chime H. Reducing the mother-to-child transmission of HIV: findings from an early infant diagnosis program in Delta state Nigeria. Int J Community Med Public Health 2017;4:4352-7. 